\title{
Use patterns of over-the-counter (OTC) medications and perspectives on OTC medications among Korean adult patients with chronic diseases: gender and age differences
}

This article was published in the following Dove Press journal:

Patient Preference and Adherence

Hyun Jeong Kim*

Young-Mo Yang*

Eun Joo Choi

Department of Pharmacy, College

of Pharmacy, Chosun University,

Gwangju, South Korea

*These authors contributed equally to this work
Correspondence: Eun Joo Choi Department of Pharmacy, College of Pharmacy, Chosun University, 309

Pilmun-daero, Dong-gu, Gwangju 61452, South Korea

Tel +82622306382

Fax +82 622225414

Email ejchoi@chosun.ac.kr

\begin{abstract}
Background: A number of symptomatic patients tend to use over-the-counter (OTC) medications and prescription medications. OTC medications can be easily obtained in pharmacies for self-treatment, but using OTC medications is not always safe and beneficial for patients. The aims of this study were to examine the use patterns of OTC medications and assess patients' perspectives regarding the use of OTC medications in Korean patients with chronic diseases.

Patients and methods: A descriptive, cross-sectional survey was carried out with Korean patients who visited the community pharmacy, located at the southern region of South Korea, during September 2015.
\end{abstract}

Results: A total of 345 patients participated in this survey. Approximately $64 \%$ of Korean survey respondents reported that they had used OTC drugs. The most commonly used OTC medications were antipyretics, analgesics and anti-inflammatory drugs. The perception level of Korean consumers on adverse drug reactions and drug-drug interactions from OTC medications was relatively low. Although OTC package leaflets are a main source of information about OTC medications, Korean consumers' level of reading OTC package leaflets was relatively low.

Conclusion: Based on these results, this study can serve as a meaningful starting point for interventions of health care professionals regarding OTC medications in South Korea. In particular, pharmacists should inform their consumers of drug-related problems from OTC drugs during consultation with the consumers; however, information about OTC drugs should be tailored to consumer information needs with the consideration of his or her circumstance. It is somewhat difficult to generalize the results from this study to other regions of South Korea since most of the respondents were probably residents of a small rural city located in the southern region of South Korea.

Keywords: over-the-counter drugs, chronic disease, community pharmacy, survey, Korea

\section{Introduction}

According to a United Nations report in 2015, the number of older people, those aged $>60$ years, has markedly increased over the last few years worldwide. ${ }^{1}$ Globally, their number is expected to increase from 901 million to 1.4 billion between 2015 and 2030, representing a growth of about 56\%. ${ }^{1}$ This increase tends to be higher in Asian countries; in Korea, the number is expected to grow by $77 \%$ during the same period. ${ }^{1}$

Along with changes in lifestyle, developments in medical technology, and increase in life expectancy, the growth in the number of older people has caused increase in the incidence and prevalence of chronic diseases (CDs) such as heart disease, hypertension 
(HTN), diabetes mellitus (DM), COPD, and cancer. ${ }^{2}$ The increase in the prevalence of CDs has led to the longterm use of multiple medications, or polypharmacy. Hence, concerns about the effects of polypharmacy in patients with CDs have been raised. ${ }^{3}$ The rise in the number of medications used by each patient contributes to increase in drug combinations, which in turn, leads to elevated risk of adverse drug reactions (ADRs) and drug-drug interactions (DDIs). ${ }^{3,4}$ According to a study by Veehof et al, elderly patients prescribed with more medications tended to experience more ADRs than other patients, and the incidence rate of ADR increased proportionally with the increase in the number of medications administered long term. ${ }^{5}$

Nowadays, a substantial number of symptomatic patients tend to use not only prescription medications but also nonprescription medications (ie, over-the-counter [OTC] medications), which can easily be obtained in pharmacies for the purpose of self-treatment. ${ }^{6,7}$ Older persons are the major consumers of OTC medications, consuming about $30 \%$ of OTC medications. ${ }^{8}$ However, OTC medications are not always safe and beneficial, and can expose the patients to unexpected health risks such as ADRs and DDIs. ${ }^{9} 10$ The incidence rates of ADRs and DDIs may be higher in patients who take both prescription and non-prescription medications. In addition, when there is no sufficient communication about the use of OTC medication between pharmacists and patients, it may lead to unintentional drug duplication (UDD) because pharmacists are poorly informed about the OTC medications that patients take. Patients under multiple medications may experience a higher frequency of UDD; therefore, it is necessary to continuously monitor the use of OTC medications and prescription medications.

Several studies on OTC medication use patterns and OTC drug-related problems (DRPs) have been conducted. ${ }^{8-14}$ However, to our knowledge, studies regarding OTC drug use patterns in Korean adult patients who visit a community pharmacy are rare. The aims of this study were to 1) examine the use patterns of OTC medications and 2) assess patients' perceptions regarding the use of OTC medications in Korean patients with CDs who visited a community pharmacy.

\section{Patients and methods}

\section{Statement of ethics}

The institutional review board (IRB) of Chosun University reviewed and approved the proposed study (21041055-ABN-01-2015-0043).

\section{Study design}

This study consisted of conducting a self-reported survey on the patient's perception on OTC medication use and collecting the patient's medical record retrospectively from the pharmacy's database. To obtain data on the patient's perception toward the use of OTC medication, the self-reported survey was conducted. Before the initiation of the survey, the aims and procedure of the study had been explained to patients thoroughly, and written informed consents were acquired from all patients who agreed to participate in the survey. Participation was voluntary, and information provided from the participants was de-identified. The average time requested for the completion of each survey was $~ 10-15$ minutes. Later, other necessary data of the survey participants were collected by reviewing their medical records from the pharmacy's database.

\section{Study sites}

To select an appropriate community pharmacy located in a small rural city where a number of elderly people ( $\geq 65$ years old) live, we called 40 community pharmacies in Namwon in the North Jeolla Province of South Korea, explained the purposes of the study, and requested participation in it. However, only one middle-sized community pharmacy agreed to participate in the study. The composition of the patients visiting this community pharmacy showed various age groups because it was located in a newly developed area of Namwon. In 2015, 85,000 people lived in Namwon, and among them, the elderly population accounted for about $24 \%$. In particular, it is highly likely that most elderly people cannot receive health services in a timely manner because they live in rural areas where there are not enough hospitals and pharmacies to provide health services to them.

\section{Study population}

To recruit participants in the study site, a poster that included the study objectives and inclusion criteria was placed on a bulletin board at the pharmacy. Researchers asked almost all patients who visited the community pharmacy for a consultation between September 1, 2015, and September 30, 2015. Approximately 4,000 patients visited the study site during the study period. Questionnaires were distributed by the researchers to all patients who agreed to participate in the survey. The patients who met the following criteria were included in the study: patients aged $\geq 18$ years and patients with CDs (defined as those who had continuously taken prescription medications due to the diseases for at least 3 months). Patients who were illiterate were excluded.

\section{Data collection}

A survey instrument was developed after reviewing published literature on OTC medication use. Prior to data collection, 
the contents of the survey instrument were reviewed by pharmacy researchers and experts, and a pilot test of the survey was conducted with 10 patients who were not considered as the study sample to ensure content validity and clarity. Minor revisions were made based on the results of the pilot test and feedback from the researchers and experts. Patients received questionnaires regarding OTC medications, which they had taken and the patients' perceptions on the use of OTC medications. A 5-point or 4-point Likert scale was used for responses to the questions about the perceptions. Patient demographic and clinical characteristics including gender, age, types of insurance, Korean standard classification of diseases, comorbidity and list of prescription drugs were retrospectively collected from the medical record by a trained community pharmacist.

\section{Statistical methods}

Responses were coded, and all analyses were performed using SAS, version 9.3 (SAS Institute Inc., Cary, NC, USA). Continuous variables were presented as mean $\pm \mathrm{SD}$, and categorical variables as frequency (n) and percentage (\%). The independent $t$-test and chi-squared or Fisher's exact tests were used to compare the differences in mean values and proportions, respectively. The a priori level of $P$-value was set at $P<0.05$. Missing data were not estimated or included in the analysis. The database, called Micromedex ${ }^{\circledR}$ Solutions (Truven Health Analytics ${ }^{\mathrm{TM}}$ ), was also utilized to analyze DDIs between prescription and OTC drugs.

\section{Results}

During the study period, 345 patients participated in this study (Figure 1). The characteristics of the survey respondents are shown in Table 1. One hundred and ninety-three $(55.9 \%)$ were female patients, and the mean age of total respondents was $61.4 \pm 12.3$ years. The majority of respondents $(91.3 \%)$ had national health insurance. The mean number of prescription medications taken by the respondents

Study subject recruitment between September 1, 2015, and September 30, 201

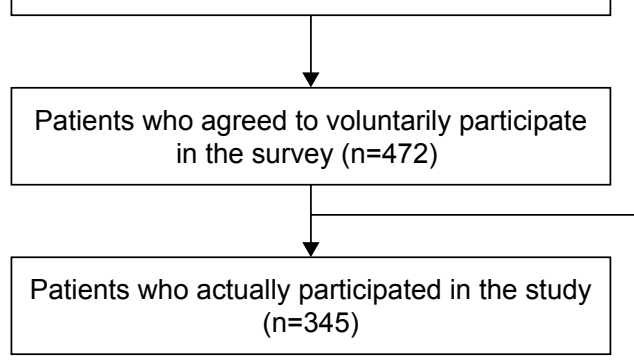

Figure I Flow diagram of steps in the selection of study subjects. was $3.7 \pm 2.2$. The most frequently diagnosed CD was HTN, followed by DM, hyperlipidemia and gastroduodenitis. The characteristics of the survey respondents listed according to the use of OTC drugs are presented in Table 2. Among 224 OTC drug users, $149(66.5 \%)$ were aged $<65$ years, and 75 (33.5\%) aged $\geq 65$ years $(P=0.012)$.

The prevalence and patterns of CDs according to gender and age are presented in Table 3. The prevalence rate of gonarthrosis was significantly higher in women than in men (5.7\% vs $0.0 \% ; P=0.003)$. The prevalence rates of HTN (87.9\% vs $77.9 \% ; P=0.020)$, gastroduodenitis $(18.9 \%$ vs $7.0 \% ; P=0.001)$, gonarthrosis $(6.8 \%$ vs $0.9 \% ; P=0.003)$, heart failure $(6.8 \%$ vs $0.5 \% ; P=0.001)$, gastroesophageal reflux disease $(4.5 \%$ vs $0.9 \% ; P=0.031)$ and muscle tension $(5.3 \%$ vs $0.5 \% ; P=0.004)$ were significantly higher in respondents aged $\geq 65$ years than in those aged $<65$ years.

The OTC drug use patterns of the survey respondents according to gender and age are presented in Table 4. The most commonly used OTC drugs were antipyretics, analgesics and anti-inflammatory drugs (43.5\%), followed by antihistamines $(25.8 \%)$, digestives $(18.0 \%)$, antitussives and expectorants (13.6\%), antacids (9.6\%) and antiemetics $(8.1 \%)$. The antipyretic, analgesic and anti-inflammatory drugs were used by $49.3 \%$ and $34.1 \%$ of respondents aged $<65$ years and $\geq 65$ years, respectively, and there was a significant difference between the two groups $(P=0.006)$. Antihistamines and antitussives/expectorants were used by $31.5 \%$ and $17.4 \%$ of respondents aged $<65$ years, and $16.7 \%$ and $7.6 \%$ of respondents aged $\geq 65$ years, respectively. There were significant differences in drug use between the two age groups (antihistamines, $P=0.002$; antitussives and expectorants, $P=0.010$ ). The use of antitussives/expectorants, antacids and antiemetics was $19.1 \%, 13.2 \%$ and $4.6 \%$ in male patients, and $9.3 \%, 6.7 \%$ and $10.9 \%$ in female patients, respectively. The difference in drug use between genders was significant for all three types of drugs (antitussives and expectorants, $P=0.009$; antacids, $P=0.044$; antiemetics, $P=0.034$ ). 
Table I Participant demographic and clinical characteristics

\begin{tabular}{ll}
\hline Characteristics & $\begin{array}{l}\text { Total, } \mathbf{n}(\%) \\
(\mathbf{n}=\mathbf{3 4 5})\end{array}$ \\
\hline Gender & \\
Male & $152(44.1)$ \\
Female & $193(55.9)$ \\
Age (years), mean \pm SD & $6 I .4 \pm 12.3$ \\
$<45$ & $21(6.1)$ \\
$45-54$ & $95(27.5)$ \\
$55-64$ & $97(28.1)$ \\
$65-74$ & $74(21.4)$ \\
$\geq 75$ & $58(16.8)$ \\
Types of insurance & \\
National health insurance & $315(91.3)$ \\
National medical aid & $29(8.4)$ \\
Industrial accident compensation insurance & $0(0.0)$ \\
Car insurance & $0(0.0)$ \\
Others & $1(0.3)$ \\
Number of prescription medications taken & $3.7 \pm 2.2$ \\
by participants, mean \pm SD & \\
$\leq$ I & $27(7.8)$ \\
$2-4$ & $228(66.1)$ \\
$5-9$ & $79(22.9)$ \\
$\geq 10$ & $11(3.2)$ \\
Ten most frequently diagnosed chronic diseases in participants \\
Hypertension & $282(81.7)$ \\
Diabetes mellitus & $104(30.1)$ \\
Hyperlipidemia & $97(28.1)$ \\
Gastroduodenitis & $40(I I .6)$ \\
Gonarthrosis & $11(3.2)$ \\
Menopausal disorders & $1 \mathrm{I}(3.2)$ \\
Heart failure & $10(2.9)$ \\
Gastroesophageal reflux disease & $8(2.3)$ \\
Dyspepsia & $8(2.3)$ \\
Muscle tension & $8(2.3)$ \\
\hline
\end{tabular}

The views of the survey respondents toward OTC drug use according to gender and age are shown in Table 5 . The most common reason for using an OTC drug was cold (28.1\%), followed by dyspepsia (22.6\%) and pain (19.4\%). In order to relieve pain, $28.3 \%$ of male patients and $12.4 \%$ of female patients used OTC medications, and the result showed a significant inter-group difference $(P<0.001)$. More respondents aged $<65$ years $(25.4 \%)$ used OTC medications to reduce pain when compared with those aged $\geq 65$ years $(9.8 \%)(P<0.001)$. Approximately $83 \%$ of the survey respondents had used OTC medications less than six times within the last 30 days. Based on a 5-point Likert scale, questions "Q3," "Q4" and "Q5" had relatively higher mean values $(3.9 \pm 0.9,4.0 \pm 1.1$ and $3.6 \pm 1.4$, respectively) than question "Q6" (2.7 \pm 1.3$)$. Only question "Q6" showed a significant difference in response $(P<0.001)$ between respondents aged $<65$ years $(2.9 \pm 1.3)$ and those aged $\geq 65$ years (2.3 \pm 1.2$)$. When a 4 -point Likert scale was used to evaluate the question "Q7," the mean was $2.2 \pm 1.2$. The mean values for question "Q7" between male (2.4 \pm 1.2$)$ and female $(2.0 \pm 1.2)$ patients were significantly different $(P=0.006)$. Similarly, there was a significant difference $(P<0.001)$ in mean values for question "Q7" between respondents aged $<65$ years $(2.5 \pm 1.2)$ and those aged $\geq 65$ years $(1.8 \pm 1.1)$.

The DDIs between prescription and OTC medications are shown in Table 6. Cilostazol and Ginkgo biloba together were most frequently used (10 cases) and concurrent use of them may cause increased risk of bleeding. Combined use of non-steroidal anti-inflammatory drugs and thiazide diuretics may reduce diuretic effectiveness and possibly cause nephrotoxicity. Increased risk of hypoglycemia may occur with concurrent use of antidiabetic agents and thioctic acid. Coadministration of diltiazem and clopidogrel may reduce the antiplatelet effect of clopidogrel and increase the risk of thrombotic events.

\section{Discussion}

In this study, we examined OTC drug use patterns and assessed patients' perceptions about OTC drug use in Korean patients with CDs who visited a community pharmacy during September 2015. The main finding of this study was that $\sim 92 \%$ of the survey respondents had taken $\geq 2$ prescription medications and about $64 \%$ of them had used OTC medications for the purpose of self-treatment. The most frequently used OTC medications were antipyretics, analgesics and antiinflammatory drugs such as acetaminophen and ibuprofen. The most common reason for using an OTC medication was to relieve cold, followed by dyspepsia and pain.

The findings revealed that about $64 \%$ (224/345) of respondents had used OTC drugs, which may be due to CDs with which the respondents had been diagnosed to some degree. Because of their CD status, patients are more likely to add supplements (eg, OTC medications) to their drug regimens in order to help improve their conditions. Gazibara et al reported that the number of $\mathrm{CD}$ treated was related to the number of OTC drugs used..$^{15}$ In other words, patients with multiple CDs may use multiple OTC drugs. Compared with the results from other studies regarding the use of OTC medications in the UK (38.0\%), Serbia (57.0\%) and Northern Ireland (32.2\%), the prevalence of OTC drug use in this study was higher. ${ }^{15-17}$ However, because the studies in the UK and Serbia were conducted with patients aged $\geq 65$ years, the prevalence of OTC medication use in this study $(21.7 \%, 75 / 345)$ was likely to be lower than that in the two countries.

Although there was no statistically significant difference, the finding that women used more OTC medications than men 
Table 2 Participant demographic and clinical characteristics according to the use of OTC medications

\begin{tabular}{|c|c|c|c|}
\hline Characteristics & $\begin{array}{l}\text { OTC medication } \\
\text { user, } n(\%)(n=224)\end{array}$ & $\begin{array}{l}\text { OTC medication } \\
\text { non-user, } n(\%)(n=|2|)\end{array}$ & $P$-value ${ }^{a}$ \\
\hline \multicolumn{4}{|l|}{ Gender } \\
\hline Male & $107(47.8)$ & $45(37.2)$ & 0.058 \\
\hline Female & $117(52.2)$ & $76(62.8)$ & \\
\hline \multicolumn{4}{|l|}{ Age (years) } \\
\hline$<65$ & $149(66.5)$ & $64(52.9)$ & 0.012 \\
\hline$\geq 65$ & $75(33.5)$ & $57(47.1)$ & \\
\hline \multicolumn{4}{|c|}{ Number of prescription medications taken by participants } \\
\hline$\leq 1$ & $19(8.5)$ & $8(6.5)$ & 0.445 \\
\hline $2-4$ & $146(65.2)$ & $82(67.8)$ & \\
\hline $5-9$ & $54(24.1)$ & $25(20.7)$ & \\
\hline$\geq 10$ & $5(2.2)$ & $6(5.0)$ & \\
\hline \multicolumn{4}{|l|}{ Chronic disease } \\
\hline Hypertension & $183(81.7)$ & $99(81.8)$ & 0.978 \\
\hline Diabetes mellitus & $62(27.7)$ & $42(34.7)$ & 0.174 \\
\hline Hyperlipidemia & $60(26.8)$ & $37(30.6)$ & 0.455 \\
\hline Gastroduodenitis & $23(10.3)$ & $17(14.0)$ & 0.295 \\
\hline Gonarthrosis & $6(2.7)$ & $5(4.1)$ & 0.463 \\
\hline Menopausal disorders & $8(3.6)$ & $3(2.5)$ & 0.582 \\
\hline Heart failure & $3(1.3)$ & $7(5.8)$ & 0.019 \\
\hline Gastroesophageal reflux disease & $4(1.8)$ & $4(3.3)$ & 0.371 \\
\hline Dyspepsia & $2(0.9)$ & $6(5.0)$ & 0.017 \\
\hline Muscle tension & $4(1.8)$ & $4(3.3)$ & 0.371 \\
\hline
\end{tabular}

Note: aChi-squared test or Fisher's exact test.

Abbreviation: OTC, over-the-counter.

was in line with the results from previous studies conducted in other countries..$^{13,15,17}$ Among the 224 respondents in this study, $52.2 \%$ were women, and among the 202 OTC medication users in Serbia, $63.4 \%$ were women. ${ }^{15}$ This higher prevalence of OTC medication use among women can be, to some degree, explained by difference in pain perception (eg, menstrual pain), higher health awareness, higher utilization of health services and better knowledge on medications..$^{13,18}$

The most frequently used OTC medications among our survey respondents were antipyretics, analgesics and anti-inflammatory drugs. This finding was in agreement with those of other studies. ${ }^{11,15,19}$ These drugs are used to relieve muscle and joint pain, headache and cold symptoms, which our survey respondents answered as the reasons for using OTC medications. Interestingly, the use of these drugs were more common in respondents aged $<65$ years $(49.3 \%)$ than those aged $\geq 65$ years $(34.1 \%)$. It was thought that the elderly, aged $\geq 65$ years, took prescription drugs instead of OTC drugs for relieving pain and cold symptoms because they could save money by utilizing

Table 3 Prevalence and patterns of chronic diseases according to gender and age

\begin{tabular}{|c|c|c|c|c|c|c|c|}
\hline \multirow[t]{2}{*}{ Chronic diseases } & \multirow{2}{*}{$\begin{array}{l}\text { Total, } \\
\text { n (\%) } \\
(n=345)\end{array}$} & \multicolumn{3}{|l|}{ Gender } & \multicolumn{3}{|l|}{ Age } \\
\hline & & $\begin{array}{l}\text { Male, n (\%) } \\
(n=152)\end{array}$ & $\begin{array}{l}\text { Female, n (\%) } \\
(n=193)\end{array}$ & $P$-value ${ }^{a}$ & $\begin{array}{l}<65 \text { years, } \\
n(\%)(n=213)\end{array}$ & $\begin{array}{l}\geq 65 \text { years } \\
n(\%)(n=132)\end{array}$ & $P$-value ${ }^{\text {a }}$ \\
\hline Hypertension & $282(81.7)$ & 121 (79.6) & I6I (83.4) & 0.363 & 166 (77.9) & I I 6 (87.9) & 0.020 \\
\hline Diabetes mellitus & $104(30.1)$ & $47(30.9)$ & $57(29.5)$ & 0.780 & $61(28.6)$ & $43(32.6)$ & 0.439 \\
\hline Hyperlipidemia & $97(28.1)$ & $37(24.3)$ & $60(31.1)$ & 0.166 & $58(27.2)$ & $39(29.5)$ & 0.642 \\
\hline Gastroduodenitis & $40(11.6)$ & $14(9.2)$ & $26(13.5)$ & 0.220 & $15(7.0)$ & $25(18.9)$ & 0.001 \\
\hline Gonarthrosis & II (3.2) & $0(0.0)$ & II (5.7) & 0.003 & $2(0.9)$ & $9(6.8)$ & 0.003 \\
\hline Menopausal disorders & II (3.2) & - & II (5.7) & - & $10(4.7)$ & I (0.8) & 0.043 \\
\hline Heart failure & $10(2.9)$ & $4(2.6)$ & $6(3.1)$ & 0.793 & I $(0.5)$ & $9(6.8)$ & 0.001 \\
\hline Gastroesophageal reflux disease & $8(2.3)$ & $4(2.6)$ & $4(2.1)$ & 0.732 & $2(0.9)$ & $6(4.5)$ & 0.031 \\
\hline Dyspepsia & $8(2.3)$ & $3(2.0)$ & $5(2.6)$ & 0.706 & $3(1.4)$ & $5(3.8)$ & 0.154 \\
\hline Muscle tension & $8(2.3)$ & $4(2.6)$ & $4(2.1)$ & 0.732 & I (0.5) & $7(5.3)$ & 0.004 \\
\hline
\end{tabular}

Note: aChi-squared test or Fisher's exact test. 
Table 4 Participants' OTC medication use patterns according to gender and age

\begin{tabular}{|c|c|c|c|c|c|c|c|}
\hline \multirow[t]{2}{*}{ OTC medication class } & \multirow{2}{*}{$\begin{array}{l}\text { Total, } \\
\text { n (\%) } \\
(n=345)\end{array}$} & \multicolumn{3}{|l|}{ Gender } & \multicolumn{3}{|l|}{ Age } \\
\hline & & $\begin{array}{l}\text { Male, } n(\%) \\
(n=152)\end{array}$ & $\begin{array}{l}\text { Female, } n(\%) \\
(n=193)\end{array}$ & $P$-value ${ }^{a}$ & $\begin{array}{l}<65 \text { years, } \\
n(\%)(n=2 \mid 3)\end{array}$ & $\begin{array}{l}\geq 65 \text { years } \\
n(\%)(n=132)\end{array}$ & $P$-value ${ }^{a}$ \\
\hline $\begin{array}{l}\text { Antipyretics, analgesics and } \\
\text { anti-inflammatory drugs }\end{array}$ & $150(43.5)$ & $66(43.4)$ & $84(43.5)$ & 0.985 & $105(49.3)$ & $45(34.1)$ & 0.006 \\
\hline Antihistamines & $89(25.8)$ & $45(29.6)$ & $44(22.8)$ & 0.151 & $67(31.5)$ & $22(16.7)$ & 0.002 \\
\hline Digestives & $62(18.0)$ & $31(20.4)$ & $31(16.1)$ & 0.298 & $40(18.8)$ & $22(16.7)$ & 0.619 \\
\hline Antitussives and expectorants & $47(13.6)$ & $29(19.1)$ & $18(9.3)$ & 0.009 & $37(17.4)$ & $10(7.6)$ & 0.010 \\
\hline Antacids & $33(9.6)$ & $20(13.2)$ & $13(6.7)$ & 0.044 & $25(11.7)$ & $8(6.1)$ & 0.081 \\
\hline Antiemetics & $28(8.1)$ & $7(4.6)$ & $21(10.9)$ & 0.034 & $17(8.0)$ & II (8.3) & 0.907 \\
\hline Multivitamins & $26(7.5)$ & II (7.2) & $15(7.8)$ & 0.852 & $13(6.1)$ & $13(9.8)$ & 0.200 \\
\hline Drugs for intestinal disorders & $17(4.9)$ & $8(5.3)$ & $9(4.7)$ & 0.798 & $14(6.6)$ & $3(2.3)$ & 0.079 \\
\hline Antispasmodics & $17(4.9)$ & $8(5.3)$ & $9(4.7)$ & 0.798 & $14(6.6)$ & $3(2.3)$ & 0.079 \\
\hline Drugs for peptic ulcer & $12(3.5)$ & $6(3.9)$ & $6(3.1)$ & 0.673 & $8(3.8)$ & $4(3.0)$ & 1.000 \\
\hline Laxatives and enemas & $7(2.0)$ & $2(1.3)$ & $5(2.6)$ & 0.472 & $6(2.8)$ & $\mathrm{I}(0.8)$ & 0.258 \\
\hline Skeletal muscle relaxants & $6(1.7)$ & $5(3.3)$ & $\mathrm{I}(0.5)$ & 0.091 & $5(2.3)$ & $\mathrm{I}(0.8)$ & 0.413 \\
\hline Contraceptives & $4(1.2)$ & - & $4(2.1)$ & - & $4(1.9)$ & - & - \\
\hline
\end{tabular}

Note: aChi-squared test or Fisher's exact test.

Abbreviation: OTC, over-the-counter.

national health insurance co-payment. According to drugs is $\leq 15,000$ won for the treatment of outpatients. ${ }^{20}$ the Korean Health Insurance Review and Assessment It was also shown that more men (19.1\%) tended to use antiService, patients aged $\geq 65$ years pay only 1,500 won tussives and expectorants than women (9.3\%). This result $(1,100$ won $=1.00$ USD) when the cost of prescription can be partially explained by a gender difference in smoking

Table 5 Participants' perspectives toward OTC medication use according to gender and age

\begin{tabular}{|c|c|c|c|c|c|c|c|}
\hline & \multirow{2}{*}{$\begin{array}{l}\text { Total, } \\
\text { n (\%) } \\
(n=345)\end{array}$} & \multicolumn{3}{|l|}{ Gender } & \multicolumn{3}{|l|}{ Age } \\
\hline & & $\begin{array}{l}\text { Male, } n(\%) \\
(n=152)\end{array}$ & $\begin{array}{l}\text { Female, } n(\%) \\
(n=193)\end{array}$ & $P$-value ${ }^{a}$ & $\begin{array}{l}<65 \text { years, } \\
n(\%)(n=2 \mid 3)\end{array}$ & $\begin{array}{l}\geq 65 \text { years } \\
n(\%)(n=132)\end{array}$ & $P$-value ${ }^{a}$ \\
\hline \multicolumn{8}{|c|}{ QI. What is your reason for using an OTC drug? } \\
\hline Pain & $67(19.4)$ & $43(28.3)$ & $24(12.4)$ & $<0.001$ & $54(25.4)$ & $13(9.8)$ & $<0.001$ \\
\hline Cold & $97(28.1)$ & $40(26.3)$ & $57(29.5)$ & 0.509 & $67(31.5)$ & $30(22.7)$ & 0.080 \\
\hline Dyspepsia & $78(22.6)$ & $37(24.3)$ & $4 I(2 I .2)$ & 0.495 & $49(23.0)$ & $29(22.0)$ & 0.823 \\
\hline Heartburn & $34(9.9)$ & $19(12.5)$ & $15(7.8)$ & 0.144 & $23(10.8)$ & II (8.3) & 0.455 \\
\hline Fatigue & $28(8.1)$ & $14(9.2)$ & $14(7.3)$ & 0.509 & $19(8.9)$ & $9(6.8)$ & 0.487 \\
\hline Diarrhea & $6(1.7)$ & $\mathrm{I}(0.7)$ & $5(2.6)$ & 0.235 & $5(2.3)$ & $\mathrm{I}(0.8)$ & 0.413 \\
\hline Constipation & $17(4.9)$ & $8(5.3)$ & $9(4.7)$ & 0.798 & $14(6.6)$ & $3(2.3)$ & 0.079 \\
\hline Others & $48(13.9)$ & $20(13.2)$ & $28(14.5)$ & 0.719 & $23(10.8)$ & $25(18.9)$ & 0.034 \\
\hline \multicolumn{8}{|c|}{ Q2. How often had you used an OTC drug within the last 30 days? } \\
\hline$<6$ & $285(82.6)$ & $129(84.9)$ & $156(80.8)$ & 0.326 & $190(89.2)$ & $95(72.0)$ & $<0.001$ \\
\hline$\geq 6$ & $60(17.4)$ & $23(15.1)$ & $37(19.2)$ & & $23(10.8)$ & $37(28.0)$ & \\
\hline \multicolumn{8}{|c|}{ Q3. Do you think that an OTC drug is effective? ${ }^{\text {b }}$} \\
\hline Mean \pm SD & $3.9 \pm 0.9$ & $4.0 \pm 1.0$ & $3.9 \pm 0.9$ & 0.573 & $3.9 \pm 0.9$ & $3.9 \pm 1.0$ & 0.754 \\
\hline \multicolumn{8}{|c|}{ Q4. Do you think that pharmacists' medication counseling is necessary when purchasing an OTC drug? ${ }^{\text {b }}$} \\
\hline Mean \pm SD & $4.0 \pm 1.1$ & $4.0 \pm 1.2$ & $4.0 \pm 1.0$ & 0.978 & $4.0 \pm 1.1$ & $4.0 \pm 1.0$ & 0.840 \\
\hline \multicolumn{8}{|c|}{ Q5. Do you give pharmacists information on drugs which you currently take when purchasing an OTC drug? ${ }^{\circ}$} \\
\hline Mean \pm SD & $3.6 \pm 1.4$ & $3.6 \pm 1.4$ & $3.6 \pm 1.4$ & 0.879 & $3.6 \pm 1.4$ & $3.7 \pm 1.3$ & 0.620 \\
\hline \multicolumn{8}{|c|}{ Q6. Do you know that an OTC drug can cause adverse reactions or interact with prescription drugs which you currently take? } \\
\hline Mean \pm SD & $2.7 \pm 1.3$ & $2.7 \pm 1.4$ & $2.7 \pm 1.3$ & 0.524 & $2.9 \pm 1.3$ & $2.3 \pm 1.2$ & $<0.001$ \\
\hline \multicolumn{8}{|c|}{ Q7. Do you read the package leaflet of an OTC drug when using it?c } \\
\hline Mean \pm SD & $2.2 \pm 1.2$ & $2.4 \pm 1.2$ & $2.0 \pm 1.2$ & 0.006 & $2.5 \pm 1.2$ & $1.8 \pm 1.1$ & $<0.001$ \\
\hline
\end{tabular}

Notes: ${ }^{a}$ Chi-squared test, Fisher's exact test or independent $t$-test. ${ }^{b}$ Rating scale: $5=$ strongly agree, $4=$ agree, $3=$ neutral, $2=$ disagree and $I=$ strongly disagree. ${ }^{c}$ Rating scale: $4=$ strongly agree, $3=$ agree, $2=$ disagree and $I=$ strongly disagree.

Abbreviation: OTC, over-the-counter. 
Table 6 Drug-drug interactions between drugs that participants had taken

\begin{tabular}{|c|c|c|c|c|c|}
\hline Drugs & Interaction drug & $\begin{array}{l}\text { Frequency } \\
\text { of use }\end{array}$ & Severity ${ }^{a}$ & $\begin{array}{l}\text { Quality of } \\
\text { evidence }^{b}\end{array}$ & Summary \\
\hline \multirow[t]{5}{*}{ Aspirin } & Thiazide & 6 & Major & Good & $\begin{array}{l}\text { Reduced diuretic effectiveness and possible } \\
\text { nephrotoxicity }\end{array}$ \\
\hline & $\begin{array}{l}\text { Atenolol, bisoprolol, } \\
\text { carvedilol }\end{array}$ & 6 & Moderate & Good & Decreased antihypertensive effect \\
\hline & Meloxicam & 2 & Major & Fair & Increased risk of bleeding \\
\hline & Ranitidine & 6 & Minor & Excellent & $\begin{array}{l}\text { Decreased plasma levels of aspirin and its } \\
\text { antiplatelet effect }\end{array}$ \\
\hline & $\mathrm{Al}(\mathrm{OH})_{2}, \mathrm{Mg}(\mathrm{OH})_{2}, \mathrm{MgO}$ & 5 & Moderate & Fair & Decreased effectiveness of aspirin \\
\hline \multirow[t]{3}{*}{ Atenolol } & Diltiazem & 1 & Major & Good & $\begin{array}{l}\text { Increased risk of hypotension, bradycardia, AV } \\
\text { conduction disturbances }\end{array}$ \\
\hline & Glimepiride, metformin & 3 & Moderate & Good & $\begin{array}{l}\text { Hypoglycemia or hyperglycemia, decreased } \\
\text { symptoms of hypoglycemia }\end{array}$ \\
\hline & $\mathrm{Al}(\mathrm{OH})_{2}, \mathrm{Mg}(\mathrm{OH})_{2}, \mathrm{CaCO}_{3}$ & 4 & Minor & Good & Decreased effectiveness of atenolol \\
\hline Belladonna & Chlorpheniramine & $\mathrm{I}$ & Minor & Fair & Excessive anticholinergic activity \\
\hline \multirow[t]{2}{*}{ Caffeine } & Alprazolam, lorazepam & 2 & Minor & Good & $\begin{array}{l}\text { Decreased sedative and anxiolytic effects of } \\
\text { alprazolam and lorazepam }\end{array}$ \\
\hline & $\begin{array}{l}\text { Estradiol valerate, } \\
\text { medroxyprogesterone }\end{array}$ & 2 & Moderate & Good & Enhanced central nervous system stimulation \\
\hline Carvedilol & Metformin, sitagliptin & 2 & Moderate & Good & $\begin{array}{l}\text { Hypoglycemia or hyperglycemia, decreased } \\
\text { symptoms of hypoglycemia }\end{array}$ \\
\hline Cilostazol & Ginkgo biloba & 10 & Major & Good & Increased risk of bleeding \\
\hline \multirow[t]{2}{*}{ Diltiazem } & Clopidogrel & 2 & Major & Excellent & $\begin{array}{l}\text { Decreased antiplatelet effect and increased risk } \\
\text { of thrombotic events }\end{array}$ \\
\hline & Ranitidine & 1 & Minor & Good & $\begin{array}{l}\text { Increased diltiazem concentrations and } \\
\text { possible cardiovascular toxicity }\end{array}$ \\
\hline \multirow[t]{3}{*}{ Fluconazole } & Atorvastatin & 1 & Major & Fair & Increased risk of myopathy or rhabdomyolysis \\
\hline & Tamsulosin & 1 & Moderate & Fair & Increased exposure of tamsulosin \\
\hline & Tramadol & 1 & Major & Fair & $\begin{array}{l}\text { Increased tramadol exposure and risk of } \\
\text { toxicity }\end{array}$ \\
\hline G. biloba & Thiazide & 3 & Moderate & Good & Increased blood pressure \\
\hline \multirow[t]{4}{*}{ Glimepiride } & Carvedilol, nebivolol & 2 & Moderate & Good & $\begin{array}{l}\text { Hypoglycemia or hyperglycemia, decreased } \\
\text { symptoms of hypoglycemia }\end{array}$ \\
\hline & Sitagliptin & 8 & Moderate & Fair & Increased risk of hypoglycemia \\
\hline & Ranitidine & 1 & Moderate & Fair & $\begin{array}{l}\text { Increased blood glucose-lowering effect and } \\
\text { increased risk of hypoglycemia }\end{array}$ \\
\hline & Thioctic acid & 4 & Major & Fair & Increased risk of hypoglycemia \\
\hline \multirow[t]{3}{*}{ Meloxicam } & $\begin{array}{l}\text { Angiotensin II receptor } \\
\text { blockers }\end{array}$ & 3 & Moderate & Excellent & $\begin{array}{l}\text { Renal dysfunction or decreased } \\
\text { antihypertensive efficacy }\end{array}$ \\
\hline & Thiazide & 3 & Major & Good & $\begin{array}{l}\text { Reduced diuretic effectiveness and possible } \\
\text { nephrotoxicity }\end{array}$ \\
\hline & Carvedilol & 1 & Moderate & Good & Decreased antihypertensive effect \\
\hline Prednisolone & Thiazide & 1 & Moderate & Fair & Hypokalemia \\
\hline Rosuvastatin & $\mathrm{Al}(\mathrm{OH})_{2}, \mathrm{Mg}(\mathrm{OH})_{2}$ & 2 & Moderate & Fair & Decreased rosuvastatin effectiveness \\
\hline \multirow[t]{2}{*}{ Thiazide } & Ibuprofen & I & Major & Good & $\begin{array}{l}\text { Reduced diuretic effectiveness and possible } \\
\text { nephrotoxicity }\end{array}$ \\
\hline & $\mathrm{CaCO}_{3}$ & 1 & Moderate & Fair & Increased risk of hypercalcemia \\
\hline Thioctic acid & Metformin, sitagliptin & 4 & Major & Fair & Increased risk of hypoglycemia \\
\hline Tramadol & Amitriptyline & 1 & Major & Fair & $\begin{array}{l}\text { Increased risk of seizure, serotonin syndrome, } \\
\text { opioid toxicity and increased levels of tramadol }\end{array}$ \\
\hline $\begin{array}{l}\text { Notes: a'Contrai } \\
\text { prevent serious } \\
\text { increase in the fre } \\
\text { controlled studie } \\
\text { poor, but pharm: } \\
\text { Abbreviation: }\end{array}$ & $\begin{array}{l}\text { - the drugs are contraindi } \\
\text { effects; moderate - the inte } \\
\text { or severity of side effects bu } \\
\text { - the existence of the inter } \\
\text { concerns lead clinicians to } \\
\text { oventricular. }\end{array}$ & concurren & $\begin{array}{l}\text { or - the in } \\
\text { atient's ce } \\
\text { native ther } \\
\text { rrough do }\end{array}$ & $\begin{array}{l}\text { Eellent }- \text { the } \\
\text { tion, but we }\end{array}$ & $\begin{array}{l}\text { Ening and/or need medical intervention to minimize or } \\
\text { ernative therapy; minor - the interaction may cause an } \\
\text { ce of the interaction has clearly been established through } \\
\text { olled studies are rare; fair - available documentation is } \\
\text { pharmacologically similar drug is good. }\end{array}$ \\
\hline
\end{tabular}


status in Korea. Kim et al reported that over five times more men than women smoked in Korea (84.0\% vs $16.0 \%){ }^{21}$

Using OTC medications is not always safe and beneficial for patients because they can be exposed to unexpected DRPs such as ADRs and DDIs. When the respondents were asked whether an OTC drug could cause adverse reactions or interact with prescription drugs, their level of awareness was lower than expected. Although it is difficult to directly compare this result with that from a study conducted with Italian drug consumers due to difference in measurement method, most Italian patients who participated in the study recognized the potential ADRs and DDIs that could result from using OTC medications. ${ }^{22}$ It was also shown that respondents aged $<65$ years better recognized the potential ADRs and DDIs of OTC drugs than those aged $\geq 65$ years. Despite the difference in age classification of patients, according to a study in Germany, participants aged $\geq 60$ years had lower awareness of OTC drug safety than those who were younger. ${ }^{13}$ This result may be partially explained by the difference in the tendency of reading package leaflets of OTC medications. In this study, more patients aged $<65$ years tended to read the package leaflets of OTC drugs than those aged $\geq 65$ years.

Our study indicated that the level of reading package leaflets of OTC drugs was relatively low, similar to that of a previous study. Among 300 survey respondents, 46.3\% reported that they read package leaflets depending on their degree of knowledge on OTC medications, while $5.7 \%$ reported to have never read them. ${ }^{13}$ However, the survey respondents did not give equal attention to all information contained in the package leaflets. Dose, indication and contraindications were the most read information; those about duration and interactions received less attention, whereas information about side effects received the least attention. ${ }^{13}$ In addition, according to a study conducted by Calamusa et al, $70.7 \%$ of survey respondents reported using the package leaflets of OTC drugs as the main source of information about OTC medications; however, only $38.1 \%$ of them reported to have completely understood the contents of the package leaflets. ${ }^{22}$ A similar result was reported in another study published in $2000 .{ }^{23}$ Furthermore, $\sim 40 \%$ of the respondents also had difficulty in calculating the maximum daily dosage based on information from the package leaflets. ${ }^{22}$

Consequently, it is important to help patients to more frequently utilize the information contained in package leaflets and to improve their understanding of functional health literacy by adopting plain language and including glossaries and additional explanations. Pharmacists are able to partially help in achieving these objectives. Previous studies showed that the recommendations of pharmacists most often affect the choice of OTC medications by patients. ${ }^{17,24,25}$ A nationwide survey conducted in Germany reported that pharmacies were the most common place where patients visited to obtain information about OTC medications. ${ }^{26} \mathrm{~A}$ systematic review by Raynor et al reported that patients preferred information about OTC medication tailored to their individual health conditions and illness by pharmacists to that prepared by manufacturers according to strict regulations. ${ }^{27}$ Moreover, as shown in this study, patients with CDs took OTC medications and prescription medications, which may increase the risk of ADRs, DDIs, and drug-disease interactions. For example, combined use of G. biloba and cilostazol, most frequently used in this study, did not strengthen an antiplatelet effect when compared with using individual agents, but $G$. biloba tended to prolong bleeding time related to cilostazol. ${ }^{28}$ These DRPs and CDs can be better managed through medication therapy management (MTM) services provided by pharmacists.

\section{Limitations}

This study has some limitations, which must be considered when interpreting the data. The first limitation of this study is the representativeness of the survey respondents. Most of the respondents were probably residents of a small city located in the southern region of South Korea. Therefore, it is somewhat difficult to generalize the results from this study to other regions (eg, metropolitan area) of South Korea. In future studies, similar surveys will have to be carried out in other regions, before the overall results can be assessed and utilized as basic data in developing total patient care programs, such as MTM services, in Korean community pharmacies. Second, we did not consider patients' non-demographic and lifestyle factors, which could affect their OTC medication use as demonstrated in previous studies..$^{29,30}$ Third, herbal medicinal preparations and functional foods are widely used in South Korea; however, we did not consider patients' use of these products, which may possibly cause various interactions with prescription/OTC medications and diseases. Finally, the results from this study may have overestimated the perspectives of the rest of the population because we excluded patients who were illiterate or had not continuously taken prescription medications for at least 3 months.

\section{Conclusion}

In Korea, OTC medications can easily be obtained at pharmacies for the purpose of self-treatment. Approximately 64\% 
of Korean survey respondents reported that they had used OTC drugs. The most commonly used OTC medications were antipyretics, analgesics and anti-inflammatory drugs, and these drugs were more commonly used by respondents aged $<65$ years than those aged $\geq 65$ years. The awareness level of Korean consumers on DRPs such as ADRs and DDIs resulting from the use of OTC medications was relatively low. Although package leaflets are the main source of information about OTC medications, Korean consumers' level of reading these package leaflets was also relatively low. Based on these results, we believe this study can be pivotal in identifying starting points for interventions by health care professionals such as doctors, pharmacists and other health care workers. In particular, pharmacists should inform their consumers of possible DRPs from OTC medications when counseling them. However, information about OTC medications should be tailored to consumers' needs, with consideration of his or her circumstance.

\section{Acknowledgment}

This work was supported by the National Research Foundation of Korea grant funded by the Korea government (NRF-2016R1C1B1015938).

\section{Disclosure}

The authors report no conflicts of interest in this work.

\section{References}

1. World Population Ageing. United Nations; 2015. Available from: http:// www.un.org/en/development/desa/population/publications/pdf/ageing/ WPA2015_Report.pdf. Accessed August 18, 2016.

2. Noncommunicable diseases (NCD). World Health Organization; 2016. Available from: http://www.who.int/gho/ncd/en/. Accessed August 19, 2016.

3. Fried TR, O’Leary J, Towle V, Goldstein MK, Trentalange M, Martin DK. Health outcomes associated with polypharmacy in community-dwelling older adults: a systematic review. J Am Geriatr Soc. 2014;62(12):2261-2272.

4. Frazier SC. Health outcomes and polypharmacy in elderly individuals: an integrated literature review. J Gerontol Nurs. 2005;31(9):4-11.

5. Veehof LJ, Stewart RE, Meyboom-de Jong B, Haaijer-Ruskamp FM. Adverse drug reactions and polypharmacy in the elderly in general practice. Eur J Clin Pharmacol. 1999;55(7):533-536.

6. Trumic E, Pranjic N, Begic L, Bečić F. Prevalence of polypharmacy and drug interaction among hospitalized patients: opportunities and responsibilities in pharmaceutical care. Mater Sociomed. 2012;24(2):68-72.

7. Alić A, Pranjić N, Ramić E. Polypharmacy and decreased cognitive abilities in elderly patients. Med Arh. 2011;65(2):102-105.

8. Stone JA, Lester CA, Aboneh EA, Phelan CH, Welch LL, Chui MA. A preliminary examination of over-the-counter medication misuse rates in older adults. Res Social Adm Pharm. 2017;13(1):187-192.

9. Zaghloul AA, Elsergany M, El-Enein NA, Alsuwaidi H, Ayoub M. Over-the-counter medication patterns in households in Sharjah, United Arab Emirates. Risk Manag Healthc Policy. 2013;7:19-24.

10. Eickhoff C, Hämmerlein A, Griese N, Schulz M. Nature and frequency of drug-related problems in self-medication (over-the-counter drugs) in daily community pharmacy practice in Germany. Pharmacoepidemiol Drug Saf. 2012;21(3):254-260.
11. Nagaraj M, Chakraborty A, Srinivas BN. A Study on the Dispensing Pattern of Over the Counter Drugs in Retail Pharmacies in Sarjapur Area, East Bangalore. J Clin Diagn Res. 2015;9(6):FC11-3.

12. Simoens S, Lobeau M, Verbeke K, van Aerschot A. Patient experiences of over-the-counter medicine purchases in Flemish community pharmacies. Pharm World Sci. 2009;31(4):450-457.

13. Barrenberg E, Garbe E. Use of over-the-counter (OTC) drugs and perceptions of OTC drug safety among German adults. Eur J Clin Pharmacol. 2015;71(11):1389-1396.

14. Wright J, Bond C, Robertson HD, Matheson C. Changes in over-thecounter drug misuse over 20 years: perceptions from Scottish pharmacists. J Public Health. 2015;pii: fdv169.

15. Gazibara T, Nurkovic S, Kisic-Tepavcevic D, et al. Pharmacotherapy and over-the-counter drug use among elderly in Belgrade, Serbia. Geriatr Nurs. 2013;34(6):486-490.

16. Poole C, Jones D, Veitch B. Relationships between prescription and non-prescription drug use in an elderly population. Arch Gerontol Geriatr. 1999;28(3):259-271.

17. Wazaify M, Shields E, Hughes CM, Mcelnay JC. Societal perspectives on over-the-counter (OTC) medicines. Fam Pract. 2005;22(2):170-176.

18. Isacson D, Bingefors K. Epidemiology of analgesic use: a gender perspective. Eur J Anaesthesiol Suppl. 2002;26(Suppl 26):5-15.

19. Cuzzolin L, Benoni G. Safety of non-prescription medicines: knowledge and attitudes of Italian pharmacy customers. Pharm World Sci. 2010; 32(1):97-102.

20. Korean Health Insurance Review \& Assessment Service. Available from: https://www.hira.or.kr/main.do. Accessed August 25, 2016.

21. Kim SM, Jung JW, Park IW, et al. Gender differences in relations of smoking status, depression, and suicidality in Korea: findings from the Korea National Health and Nutrition Examination Survey 2008-2012. Psychiatry Investig. 2016;13(2):239-246.

22. Calamusa A, di Marzio A, Cristofani R, et al. Factors that influence Italian consumers' understanding of over-the-counter medicines and risk perception. Patient Educ Couns. 2012;87(3):395-401.

23. Bernardini C, Ambrogi V, Perioli LC, Tiralti MC, Fardella G. Comprehensibility of the package leaflets of all medicinal products for human use: a questionnaire survey about the use of symbols and pictograms. Pharmacol Res. 2000;41(6):679-688.

24. Hayashi M, Masuda S, Kimura H. Key information providers, channels, and characteristics of Japanese consumers' informed choices of over-the-counter medications. Springerplus. 2015;4:737.

25. Aoyama I, Koyama S, Hibino H. Self-medication behaviors among Japanese consumers: sex, age, and SES differences and caregivers' attitudes toward their children's health management. Asia Pac Fam Med. 2012;11(1):7.

26. Eichenberg C, Auersperg F, Rusch BD, Brähler E. Self-Medication: A Nationwide Representative Survey on Motives, Reasons and Sources on Consuming Over-the-Counter Medication. Psychother Psychosom Med Psychol. 2015;65(8):304-310.

27. Raynor DK, Blenkinsopp A, Knapp P, et al. A systematic review of quantitative and qualitative research on the role and effectiveness of written information available to patients about individual medicines. Health Technol Assess. 2007;11(5):1-160.

28. Aruna D, Naidu MU. Pharmacodynamic interaction studies of Ginkgo biloba with cilostazol and clopidogrel in healthy human subjects. Br J Clin Pharmacol. 2007;63(3):333-338.

29. Morales-Suárez-Varela M, Llopis-González A, Caamaño-Isorna F, Gimeno-Clemente N, Ruiz-Rojo E, Rojo-Moreno L. Adolescents in Spain: use of medicines and adolescent lifestyles. Pharm World Sci. 2009;31(6):656-663.

30. Villako P, Volmer D, Raal A. Factors influencing purchase of and counselling about prescription and OTC medicines at community pharmacies in Tallinn, Estonia. Acta Pol Pharm. 2012;69(2):335-340. 


\section{Publish your work in this journal}

Patient Preference and Adherence is an international, peer-reviewed, open access journal that focuses on the growing importance of patient preference and adherence throughout the therapeutic continuum. Patient satisfaction, acceptability, quality of life, compliance, persistence and their role in developing new therapeutic modalities and compounds to optimize

clinical outcomes for existing disease states are major areas of interest for the journal. This journal has been accepted for indexing on PubMed Central. The manuscript management system is completely online and includes a very quick and fair peer-review system, which is all easy to use. Visit http://www. dovepress.com/testimonials.php to read real quotes from published authors.

Submit your manuscript here: http://www.dovepress.com/patient-preference-and-adherence-journal 